Article

\title{
Electrolyte Effects on Poly (Acrylic Acid)-Based Aircraft De-icing Fluids
}

\author{
Yuchen Wang ${ }^{1}$, Nicholas E. Hudson ${ }^{2}$, Richard A. Pethrick ${ }^{2,+}$ and Carl J. Schaschke ${ }^{3, *(\mathbb{D}}$ \\ 1 Department of Chemical and Process Engineering, University of Strathclyde, 75 Montrose Street, Glasgow, \\ Scotland G1 1XJ, UK; yuchen.wang@strath.ac.uk \\ 2 Department of Pure and Applied Chemistry, University of Strathclyde, 295 Cathedral Street, Glasgow, \\ Scotland G1 1XL, UK; n.e.hudson@strath.ac.uk \\ 3 School of Computing, Engineering and Physical Sciences, University of the West of Scotland, Paisley, \\ Scotland PA1 2BE, UK \\ * Correspondence: carl.schaschke@uws.ac.uk; Tel.: +44-141-848-3914 \\ + Deceased.
}

Received: 25 April 2019; Accepted: 29 May 2019; Published: 1 June 2019

\begin{abstract}
Poly (acrylic acid) [PAA]-based aircraft de-icing fluids are widely used commercially but are known to be subject to the formation of insoluble gel particles within wing structures. In this study, the rheological effects of the sodium chloride, potassium formate, and calcium acetate with commercially used PAA-based fluids are reported across the temperature range of -15 to $15^{\circ} \mathrm{C}$. Calcium ions have the potential to create gel particles, reflected in the shifts in the viscosity-temperature profile, while PAA aggregation is influenced by the concentrations and compositions of sodium and potassium salts in the water used for dilution. From the data presented, it is possible to create de-icing fluid formulations with the necessary rheological characteristics from stock solutions by dilution using available water sources, providing that the ion concentration is known.
\end{abstract}

Keywords: poly (acrylic acid); water/glycol mixtures; polyelectrolytes; salt effects; rheology; calcium and potassium ions

\section{Introduction}

In a previous paper [1], the effects of varying $\mathrm{NaCl}$ concentrations on the viscosity profiles for poly (acrylic acid) [PAA]/water/glycol/salt mixtures were reported, in which it was found that a maximum in the shear viscosity at approximately $0{ }^{\circ} \mathrm{C}$ corresponded to an optimal liquid for de-icing applications. Ice build-up on aircrafts arises when the temperature falls below $0{ }^{\circ} \mathrm{C}$ on cold surfaces, particularly after long flights at high altitude or during re-fueling in the presence of high humidity. The presence of ice on wings influences the aerodynamic efficiency of the ailerons and influences performance both during and after take-off. The recommendations in relation to de-icing and anti-icing of aircrafts are summarized in the Association of European Airlines and United States directives [2-4]. The formation of insoluble gel deposits on control surfaces and beneath ailerons is a consequential problem of airport and aircraft de-icing $[5,6]$. In this paper, we explore the effects of calcium and potassium ions on the viscosity characteristics of commercially used PAA mixtures and on the ability to form a gel phase. This can occur through the preparation and application of the de-icing fluid either by dilution and mixing of stock solutions with local water supplies, or by way of contamination with residues deposited under the wings from runway de-icing fluids. Gel formation may possess potential undesirable rheological characteristics.

The aircraft de-icing process involves the application of shear-thinning non-Newtonian fluids at approximately $60^{\circ} \mathrm{C}$ in order to disperse ice and deposit a liquid layer, which is shed during take-off 
due to the high shear caused by air movement over the surface on which fluid has been applied. The fluid requires an adequate viscosity to stay on the flight surfaces whilst the aircraft is on stand or taxiing at low speed, but must be rapidly shed during the initial stages of (high speed) take-off. There are cases of aircrafts, however, that have been prone to a build-up of gel deposits around the ailerons when operated for prolonged periods in inclement weather $[5,6]$ and have been associated with a number of incidents [6-12]. The loss of flight control is often associated with insoluble PAA gel residues around bearings beneath the wings [6-12]. Runway de-icing usually involves aqueous mixtures of sodium and potassium ethanoate salts. These mixtures are used in extreme conditions and have been the subject of environmental concerns [13-15]. A number of alternative formulations have been proposed based on glucoside, ethoxy, and protein structures, which, in combination with various inorganic salts, depress the freezing point of water $[4,16]$. Such formulations have been developed to reduce the biological oxygen demand (BOD) of the waste water run-off. These fluids are not normally used for aircraft de-icing.

Depending on the severity of the weather, particular types of de-icing are recommended. De-icing fluids normally consist of propylene glycol/water mixtures for the purpose of depressing the freezing point. Poly (acrylic acid) provides the desired thickening characteristics to enable the fluids to settle on the aircraft surface under low shear conditions, such as standing or taxiing, and to flow off easily when the air shear increases during take-off. De-icing fluids are normally produced with a neutral $\mathrm{pH}$ of 7.0. An inert electrolyte such as sodium chloride is added to reduce the viscosity and allow easy dispersion, while retaining the ability to be easily removed when the air velocity is increased during take-off.

A Type I fluid is used for straightforward de-icing and is usually based on a mixture of ethylene glycol or 1,2-propylene glycol, water, corrosion inhibitors, surfactants, and $\mathrm{pH}$ regulators. The de-icing fluid is sprayed onto an aircraft surface at between 65 to $80^{\circ} \mathrm{C}[17,18]$. The period of time over which ice formation is suppressed, known as the hold-over time, is relatively short, and is around three minutes in freezing rain and $20 \mathrm{~min}$ in frost-forming conditions. For longer hold-over times, a two-step de-icing process is often used, which involves the use of a Type I fluid followed by application of other types of fluids known as Type II, III, or IV fluids [19-21]. With appropriate thickening agents, hold-over times of $30 \mathrm{~min}$ for a Type II fluid in freezing rain and $240 \mathrm{~min}$ in frost-forming conditions are prescribed by the Association of European Airlines (AEA) [2,9]. While ethylene glycol is potentially harmful to both humans and animals, it does have many desirable characteristics. Propylene glycol, on the other hand, has a lower toxicity and is usually used as a base for most formulations. The melting point of aqueous mixtures of propylene glycol containing $40 \%$ glycol is $-5{ }^{\circ} \mathrm{C}$, and is lowered to $-25^{\circ} \mathrm{C}$ for fluids containing $50 \%$ glycol, and lowered further still to $-60{ }^{\circ} \mathrm{C}$ for fluids containing $60 \%$ glycol. The viscosities of the fluids at these low temperatures, however, are too high to be considered to be of practical use. For operation below $-32{ }^{\circ} \mathrm{C}$, ethylene glycol is required, although 1,3-propylene glycol is considered to be a more environmentally acceptable fluid [22].

Previous studies have shown that the addition of calcium ions to PAA-thickened fluids can lead to the formation of a gel-like precipitate [22-26]. Calcium ions may be present in water supplies commonly used to dilute the de-icing fluids prior to their use. Dilution of the de-icing fluid with hard water or its interaction with runway de-icing fluids which contain potassium formate are thought to be factors which influence gel formation. The calcium ion content in ground water can vary from below concentrations of $60 \mathrm{mg} \mathrm{L}^{-1}$ to in excess of $200 \mathrm{mg} \mathrm{L}^{-1}$. Sodium and potassium ion concentrations, which increase with water hardness, can also influence the nature of the PAA in solutions by influencing the inter-polymer interactions of PAA in aqueous solutions which, in turn, influence its effective size and hence rheological properties in solution. Sodium chloride has been identified as having toxicological effects on sparrows and has raised concerns in relation to airport waste [23].

At high dilutions, most of the carboxylic acid groups of PAA ionize, and their mutual repulsion dictates the size of the polymer chain. As the polymer concentration increases, the extent to which the carboxylic groups on the macromolecular chain are dissociated decrease, changing the effective size of the polymer. Changes in $\mathrm{pH}$ also influence the conformations and sizes of polymer molecules. 
For a polyelectrolyte system, the change in polymer interactions leads to significant changes in the rheological characteristics of the fluids [1,24-27].

Significant effects on the temperature dependence of the viscosity and wind tunnel behavior arise with the variation of the concentration of a monovalent electrolyte when added to PAA-containing fluids [28-32]. The hydrodynamic volume and polymer flexibility can be influenced by interactions of monovalent cations with the carboxylic acid groups of PAA, forming ladder-type complexes with themselves [24]. The aim of this investigation is therefore to examine the sensitivity of PAA-thickened de-icing fluids to the addition of mono- and bivalent cations thought to be responsible for the formation of the insoluble gel particles, and typically encountered in the preparation of de-icing fluids by dilution of available water sources, for aiding guidelines for the design of de-icing fluids or understanding the effects of de-icing fluid preparation.

\section{Materials and Methods}

\subsection{Materials and Sample Preparation}

Poly (acrylic acid) polymer was obtained as flocculated solid particles with approximate diameters of $0.2 \mu \mathrm{m}$ from Lubrizol (Brussels, Belgium) and of nominal molar mass of $4 \mathrm{MDa}$. Dispersion of the polymer was achieved using a Silverson L4R high shear mixer placed in a $1.0 \mathrm{~L}$ beaker containing $600 \mathrm{~g}$ of de-ionized water and operated at $4800 \mathrm{rpm}$ for $5 \mathrm{~min}$, after which the rotation speed was reduced to $3600 \mathrm{rpm}$ and continuously stirred for a further $55 \mathrm{~min}$. At a polymer concentration of $1.22 \mathrm{~g} \mathrm{dL}^{-1}$, a 'gel-like' dispersion was produced.

\subsection{Rheology Measurements}

A shear stress-controlled Carri-Med CSL 2500 rheometer (TA Instruments, Crawley, UK) using a $4 \mathrm{~cm}$ diameter parallel plate fitted with a solvent trap was used for the viscosity measurements. The temperature was maintained using a Peltier effect controller combined with an anti-freezing bath maintained at $0{ }^{\circ} \mathrm{C}$, enabling temperatures between 15 and $-15^{\circ} \mathrm{C}$ to be achieved. For the experiments in which the temperature was decreased, a cooling rate of $1.0^{\circ} \mathrm{C}$ per two minutes from 15 to $-15^{\circ} \mathrm{C}$ was used, followed by heating up to a temperature of $15^{\circ} \mathrm{C}$. Measurements were performed at shear stresses of 5 and $10 \mathrm{~Pa}$. All tests were repeated and found to provide excellent reproducibility. Tests for thixotropy using stress sweeps were outside the scope of this study, since the purpose of de-icing fluids is to adhere to a surface and have the ability to be removed at the point of take-off.

\subsection{Test of the Gelation Characteristics of PAA Mixtures}

A form of PAA, known as Carbomer A, with a nominal molecular weight of 4 MDa was used in this study. Commercially available Carbomer is available in a range of molecular weights and branched contents, and may contain vinyl pentearythritol if branched. During the drying process, it can form anhydride crosslinks, which can increase the rigidity of the backbone and increase the molecular weight.

In this study, a base fluid was used, which comprised a 50:50 (wt/wt) mono-propylene glycol/water mixture thickened with $0.30 \mathrm{~g} \mathrm{dL}^{-1}$ of Carbomer A with the addition of $0.060 \mathrm{wt} \% \mathrm{NaCl}$. A concentration of Carbomer A of $0.30 \mathrm{~g} \mathrm{dL}^{-1}$ had been previously found using wind tunnel testing to have the desired characteristics for a de-icing fluid [1]. Various diluting agents involving artificial hard water, containing $\mathrm{Ca}^{2+} 400 \pm 5 \mathrm{mg} \mathrm{L}^{-1}$ and $\mathrm{Mg}^{2+} 280 \pm 5 \mathrm{mg} \mathrm{L}^{-1}$, were formulated by dissolving calcium acetate and sodium chloride in de-ionized water. The parent fluid was then diluted to achieve concentrations of 75 and $50 \mathrm{wt} \%$. The Carbomer A-thickened fluid was prepared using the standard procedure, and potassium formate added to replace—or partly replace- the sodium chloride. Solutions were prepared with various Carbomer A concentrations. The corresponding salt concentrations are shown in Tables 1 and 2 , respectively. 
Table 1. Carbomer A additions to 50:50 (wt/wt) mono-propylene glycol/water mixtures.

\begin{tabular}{cc}
\hline Fluid Name & Carbomer A Concentraton $\left(\mathrm{g} \mathrm{dL}^{-\mathbf{1}}\right)$ \\
\hline A1 & 0.2145 \\
A2 & 0.1608 \\
A3 & 0.1072 \\
A4 & 0.0804 \\
A5 & 0.0536 \\
A6 & 0.0268 \\
\hline
\end{tabular}

Table 2. Table 1 fluids with cation additions.

\begin{tabular}{cc}
\hline Fluid Name & Cation Concentration (\%) \\
\hline A1K & $0.03 \% \mathrm{~K}^{+}$ \\
A1N & $0.03 \% \mathrm{Na}^{+}$ \\
A2K & $0.06 \% \mathrm{~K}^{+}$ \\
A2N & $0.06 \% \mathrm{Na}^{+}$ \\
A3K & $0.03 \% \mathrm{Na}^{+}$and $0.045 \% \mathrm{~K}^{+}$ \\
A3N & $0.075 \% \mathrm{Na}^{+}$ \\
\hline
\end{tabular}

\section{Results}

\subsection{Intrinsic Viscosity Measurements}

The intrinsic viscosity of Carbomer A was measured using a Ubbelohde suspended level viscometer, with the viscometer being cleaned prior to use by washing with nitric acid and rinsing with de-ionized water. The Carbomer A was dispersed in de-ionized water and left to dissolve for five days. The initial concentration was $0.0891 \mathrm{~g} \mathrm{dL}^{-1}$, and a series of solutions with different concentrations were prepared using $0.012 \mathrm{M}$ solution of neutral $\mathrm{NaCl}$. Using the Mark-Houwink coefficient values from literature [33-35], the $\mathrm{M}_{\mathrm{n}}$ was calculated to be $3.86 \times 10^{6} \mathrm{~g} \mathrm{~mol}^{-1}$ for the polymer chain adopting an extended conformation.

\subsection{Concentration Dependence of Viscosity for Carbomer A}

Measurements of the concentration dependence on viscosity for Carbomer A are shown in Figure 1 . The relative viscosity profile forms two distinct regions, where at low concentrations below $2.1 \times 10^{-2} \mathrm{~g} \mathrm{dL}^{-1}$, the polymer behaves as an isolated chain, whereas above this value, polymer-polymer interactions are evident. The viscosity is relative to an arbitrary shear rate of $10^{-6} \mathrm{~s}^{-1}$. We have previously shown that the shear rate dependence of solutions above $2.1 \times 10^{-2} \mathrm{~g} \mathrm{dL}^{-1}$ can be modelled using a modified form of the reptation model [1].

A feature of thickened de-icing fluids is the dynamic yield shear stress. The yield stresses of viscoplastic materials are well documented [36,37], and are often found in concentrated suspensions and fluids containing particles of colloidal size. Figure 2 shows that the gradient for a Carbomer A concentration of $0.241 \mathrm{~g} \mathrm{dL}^{-1}$ changes at a viscosity of approximately $10^{4} \mathrm{~Pa} \cdot \mathrm{s}$ and a stress of approximately 1 to $2 \mathrm{~Pa}$. When the concentration is reduced to $0.1608 \mathrm{~g} \mathrm{dL}^{-1}$, the critical point is lowered to a viscosity of $1.5 \times 10^{3}$ and a stress of approximately 0.9 to $1.5 \mathrm{~Pa}$. Further reducing the polymer concentration to $0.1072 \mathrm{~g} \mathrm{dL}^{-1}$ lowers the critical viscosity to $2 \times 10^{2} \mathrm{~Pa} \cdot \mathrm{s}$ and the critical stress to between 0.3 and $0.45 \mathrm{~Pa}$. Decreasing the polymer concentration to $0.0804 \mathrm{~g} \mathrm{dL}^{-1}$ reverses the effect, with an increased critical value of $5 \times 10^{2} \mathrm{~Pa} \cdot \mathrm{s}$ and a stress level of 0.02 to $0.03 \mathrm{~Pa}$. Further reducing the concentration to $0.0536 \mathrm{~g} \mathrm{dL}^{-1}$ lowers the viscosity to approximately $1.5 \mathrm{~Pa} \cdot \mathrm{s}$ and the stress to $0.015 \mathrm{~Pa}$. For lower concentrations, there is no change of viscosity when the shear stress level is increased. 


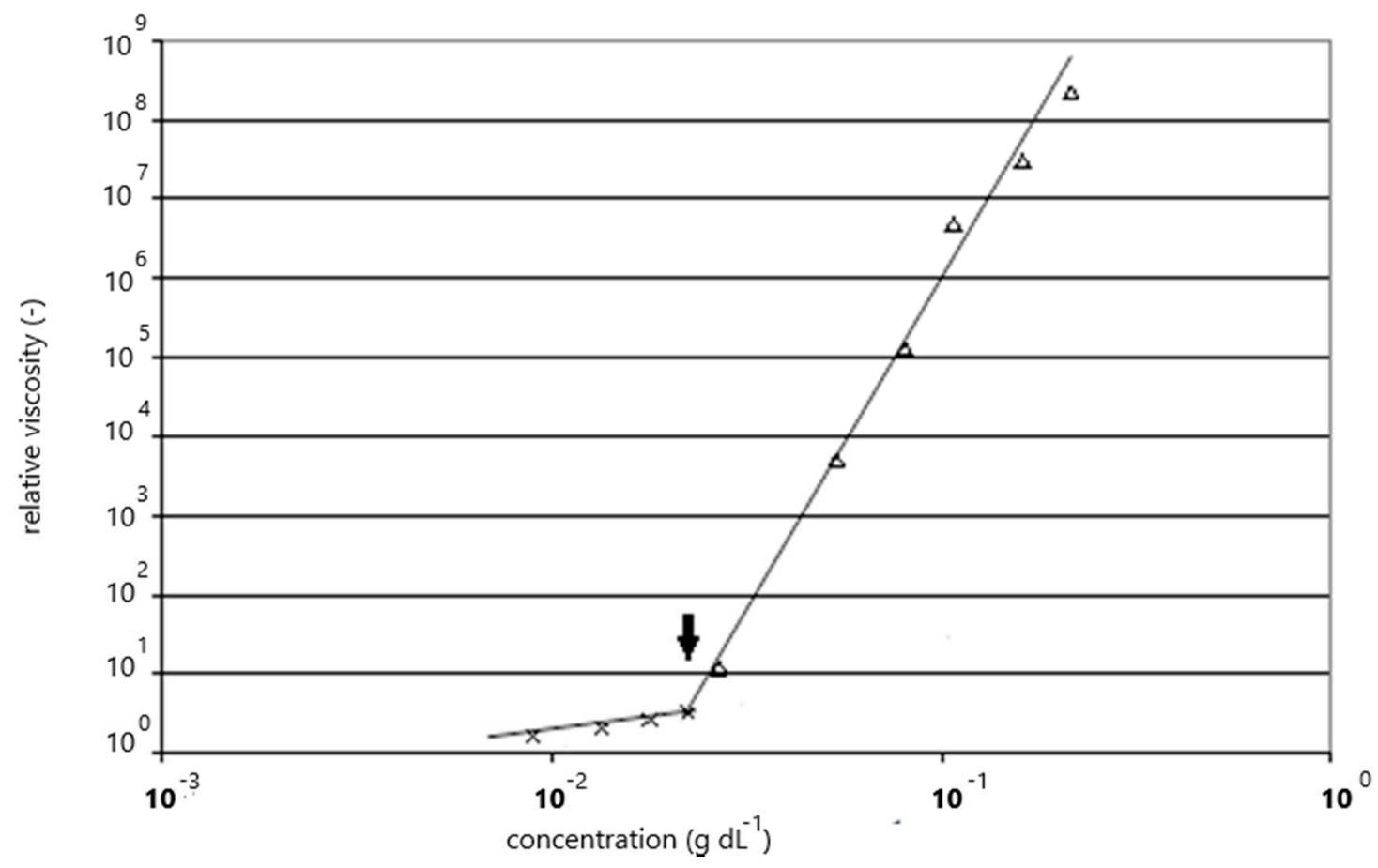

Figure 1. Relative viscosity with Carbomer A concentrations at $15^{\circ} \mathrm{C}$.

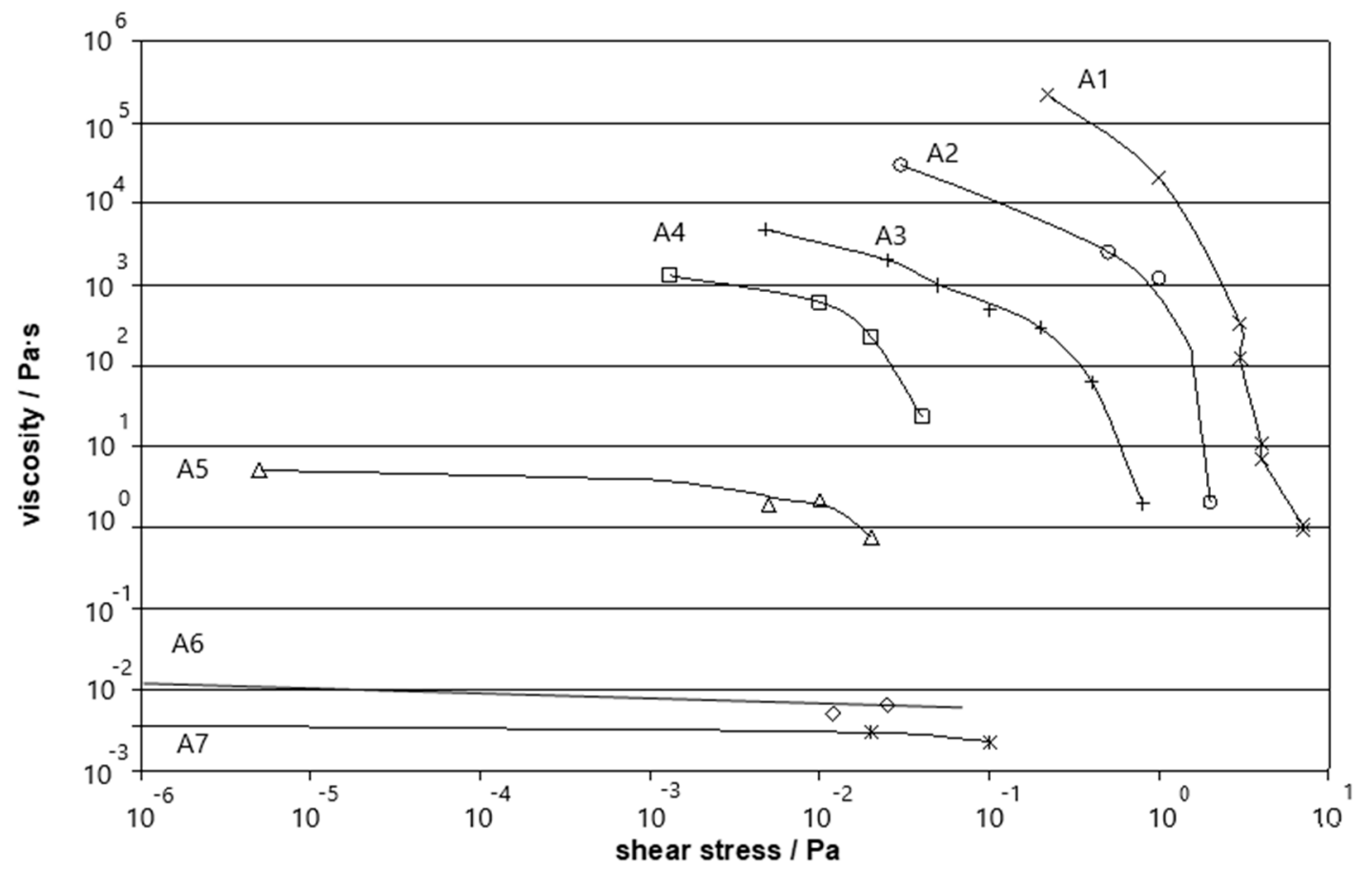

Figure 2. Viscosity/shear stress plots for Carbomer A at $15^{\circ} \mathrm{C}$. Symbols refer to the fluids in Table 1.

The implication is that as the aircraft initiates its take-off, the shear stress increases over the exposed surfaces, leading to the removal of the de-icing fluid ice as the air flow increases.

\subsection{Influence of Salt}

De-icing fluids are typically prepared as glycol/water mixtures where, prior to usage, they are diluted by $75 \%$ or $50 \%$ of their initial concentration by the addition of water. The level of hardness of 
the water avialable for use in the dilution process is dependent on the presence of dissolved minerals: Soft water has a concentration of up to $60 \mathrm{mg} \mathrm{L}^{-1}$, while moderately hard water ranges from 61 to $120 \mathrm{mg} \mathrm{L}^{-1}$. Hard water ranges from 121 to $180 \mathrm{mg} \mathrm{L}^{-1}$, while very hard water is in excess of $181 \mathrm{mg} \mathrm{L}^{-1}$. In general, $\mathrm{Ca}^{2+}$ and $\mathrm{Mg}^{2+}$ ions are the dominant species.

The presence of calcium ions is thought to be a contributor to insoluble gel formation in the under-wing areas of aircraft. A series of titration tests were therefore carried out using $0.2 \mathrm{M}$ calcium acetate to determine the critical concentration required to induce complex formation and the generation of insoluble precipitates. As the calcium ion content gradually increased, the appearance of the fluid changed from clear (phase I) to slight cloudy but without the formation of visible precipitates (phase II), and then to a cloudy liquid with a visible precipitate forming at the bottom of the container (phase III), and, finally, total phase separation with a clear layer of liquid separating from the precipitated gel layer (phase IV). The critical calcium ion concentrations at which the transition between phases were found to occur were found to be $103.9 \mathrm{mg} \mathrm{L}^{-1}$ between phases I and II, $152 \mathrm{mg} \mathrm{L}^{-1}$ between phases II and III, and $430.8 \mathrm{mg} \mathrm{L}^{-1}$ between phases III and IV.

A base fluid was formed from Carbomer $\mathrm{A}$ at a concentration of $0.3 \mathrm{~g} \mathrm{dL}^{-1}$, with $0.060 \mathrm{wt} \%$ of sodium chloride dispersed in a 50:50 (wt/wt) mono-propylene glycol/water mixture and diluted with the above artificial diluents, the base fluid having first been diluted with de-ionized water (Figure 3).

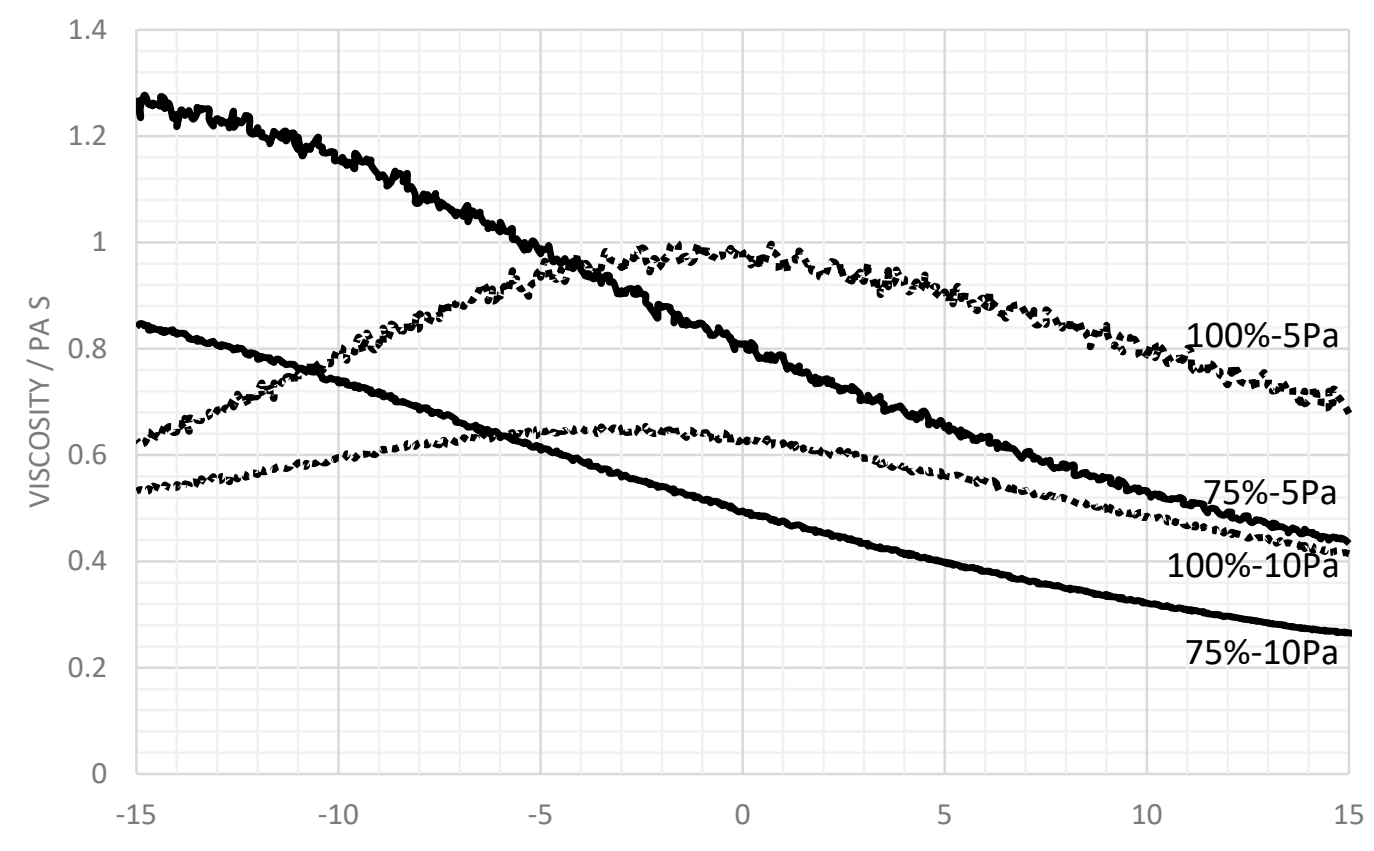

TEMPERATURE $/{ }^{\circ} \mathrm{C}$

Figure 3. Viscosity variation for the base fluid and a $75 \mathrm{wt} \%$ dilution at shear stresses of 5 and $10 \mathrm{~Pa}$.

While the diluted and undiluted base fluids exhibited lower viscosity profiles at a shear stress $10 \mathrm{~Pa}$ than at $5 \mathrm{~Pa}$, the viscosity of the base fluid at $5 \mathrm{~Pa}$ rose continuously from approximately $0.43 \mathrm{~Pa} \cdot \mathrm{s}$ at $15^{\circ} \mathrm{C}$ to $1.27 \mathrm{~Pa} \cdot \mathrm{s}$ at $-15^{\circ} \mathrm{C}$. This viscosity profile is notably different from that of the base parent fluid in two major aspects: i) At $15{ }^{\circ} \mathrm{C}$, the $75 \%$ dilution has a $60 \%$ lower viscosity, while at $-15{ }^{\circ} \mathrm{C}$, the viscosity is approximately twice that of its base parent fluid; and ii) the $75 \%$ dilution did not exhibit a viscosity 'peak' within the temperature range, whilst the viscosity of its parent fluid reached a peak value. Dilution therefore not only reduces the polymer concentration, which lowers the probability of polymer entanglement, but also reduces the level of electrolyte, which leads to changes in the chain conformation.

To explore the effects of the addition of calcium ions, measurements were performed in which the concentration of calcium ions was increased. Figure 4 illustrates that an increase in calcium ion 
concentration produces a decrease in the viscosity of the fluid. This is the result of divalent cations forming a bridge between neighboring carboxylic acid groups and thus promoting a gel formation. Dilution with $200 \mathrm{mg} \mathrm{L}^{-1}$ calcium ions lowers the viscosity from 0.81 to $0.39 \mathrm{~Pa} \cdot \mathrm{s}$ at $0{ }^{\circ} \mathrm{C}$, and from 1.27 to $0.40 \mathrm{~Pa} \cdot \mathrm{s}$ at $-15^{\circ} \mathrm{C}$. The viscosity level at this dilution changed insignificantly across the temperature range, which can be considered to be a desirable property. The general viscosity level, however, is considerably lower compared to the parent fluid and would be considered insufficient as a useful de-icing medium.

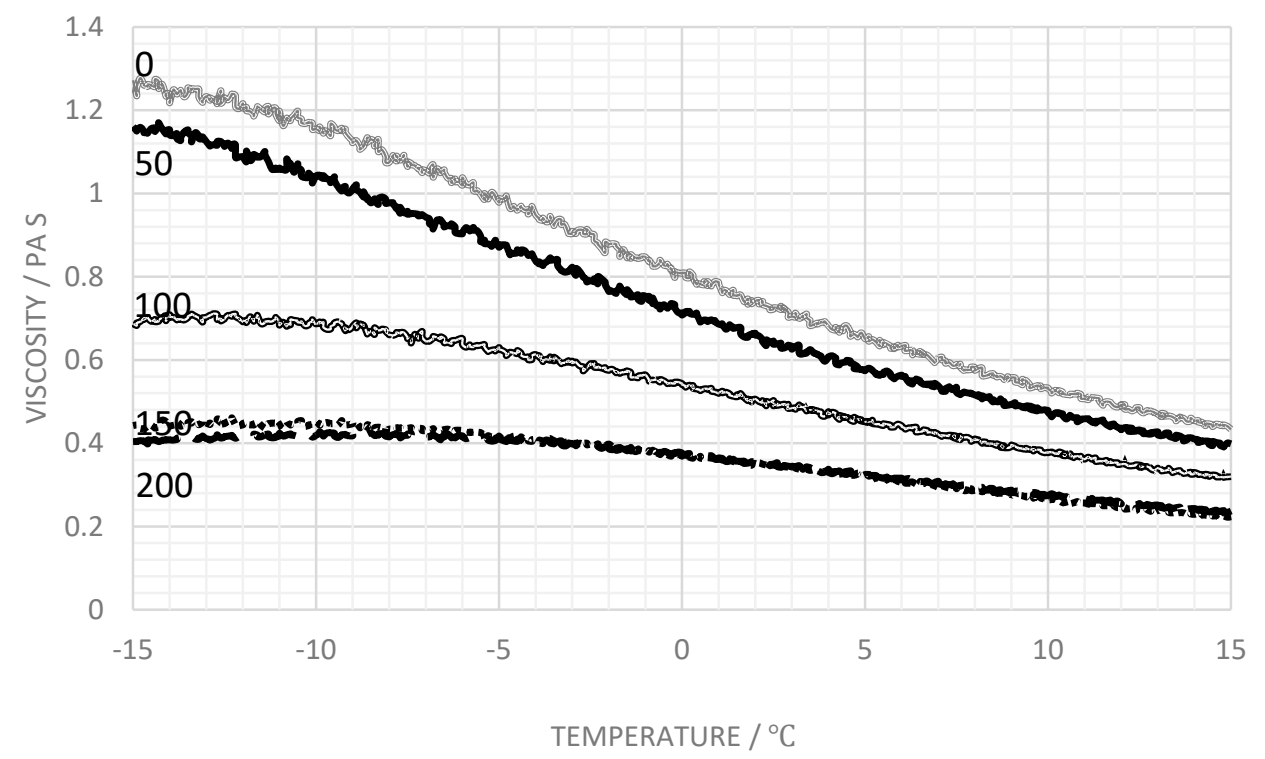

Figure 4. Viscosity variation for a $75 \mathrm{wt} \%$ dilution of Carbomer A with increasing $\mathrm{Ca}^{2+}\left(\mathrm{mg} \mathrm{L}^{-1}\right)$, at a shear stress of $5 \mathrm{~Pa}$.

By maintaining the calcium level at $50 \mathrm{mg} \mathrm{L}^{-1}$, which falls between the typical high and low values of $40-80 \mathrm{mgL}^{-1}$ found in water, and progressively increasing the sodium concentration to $100 \mathrm{mg} \mathrm{L}^{-1}$ and then to $200 \mathrm{mg} \mathrm{L}^{-1}$, there is a decrease in the viscosity in the fluid across the temperature range (Figure 5). While the presence of divalent cations is capable of producing insoluble precipitates, in this set of experiments, no visible precipitate was formed during the dilution process. It is possible that if these gels were to dry, the resulting precipitate would be difficult to re-dissolve. Changing the total salt concentration influences the chain conformation, and hence the rheology.

Potassium formate, used in the de-icing of runways, has a different ability to interact with water and with PAA by influencing the inter-polymer interactions of PAA in aqueous solutions. This influences its effective size, and thus the rheological properties. To explore the possible effects of the total salt concentration and the influence of sodium and potassium ion concentrations on the rheological properties, the viscosity and number of salt combinations were examined.

Figure 6 shows the viscosity variation with temperature for sample fluids with the same electrolyte concentrations, $0.030 \mathrm{wt} \%$, at applied shear stresses of 5 and $10 \mathrm{~Pa}$.

For an applied shear stress of $5 \mathrm{~Pa}$, the viscosity of the formulation with potassium formate (A1K) increased from approximately $1.15 \mathrm{~Pa} \cdot \mathrm{s}$ at $15^{\circ} \mathrm{C}$ to a maximum value of $1.97 \mathrm{~Pa} \cdot \mathrm{s}$ at $-3.1^{\circ} \mathrm{C}$, and then decreased to $1.45 \mathrm{~Pa} \cdot \mathrm{s}$ at $-15^{\circ} \mathrm{C}$. The viscosity is considerably lower than for the same formulation but with sodium (A1N). The 'peak' locations for both fluids, however, appeared at nearly identical temperatures. The same phenomenon occurred when the shear stress was increased to $10 \mathrm{~Pa}$. Similar behavior was also exhibited for samples with $0.060 \mathrm{wt} \%$ electrolyte addition (Figure 7). Since potassium is monovalent, it may be expected to have similar interactions with the polymer as sodium. It is known, however, to exhibit a different hydration energy, and therefore will have a different ability to interact with the carboxyl groups. The data presented in Figure 7 suggest that potassium ions have a 
greater ability to suppress the viscosity level compared to sodium ions. The location of the peak in the viscosity is slightly shifted to higher temperatures.

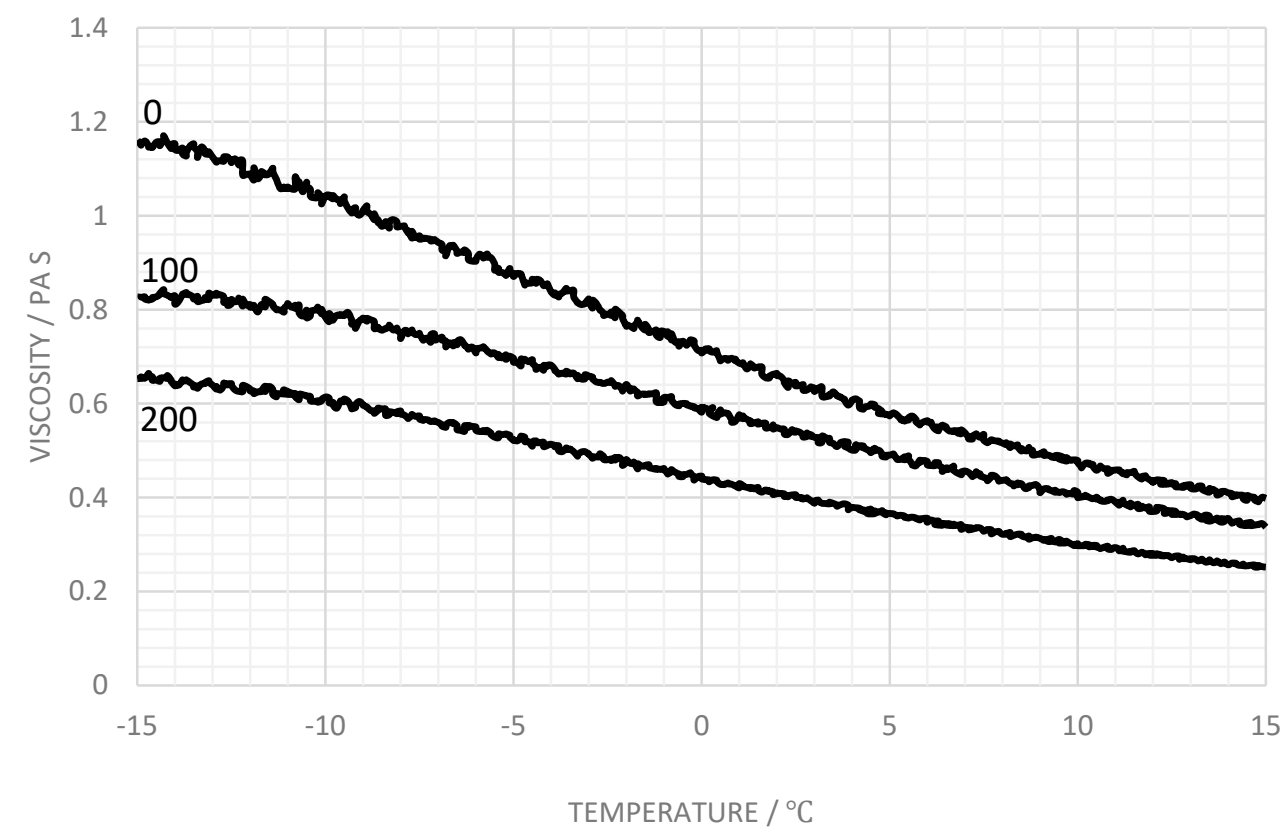

Figure 5. Viscosity variation for the $75 \mathrm{wt} \%$ Carbomer A solution containing $50 \mathrm{mg} \mathrm{L}^{-1} \mathrm{Ca}^{2+}$ with additions of 0,100 , and $200 \mathrm{mg} \mathrm{L}^{-1} \mathrm{Na}^{+}$at a shear stress of $5 \mathrm{~Pa}$.

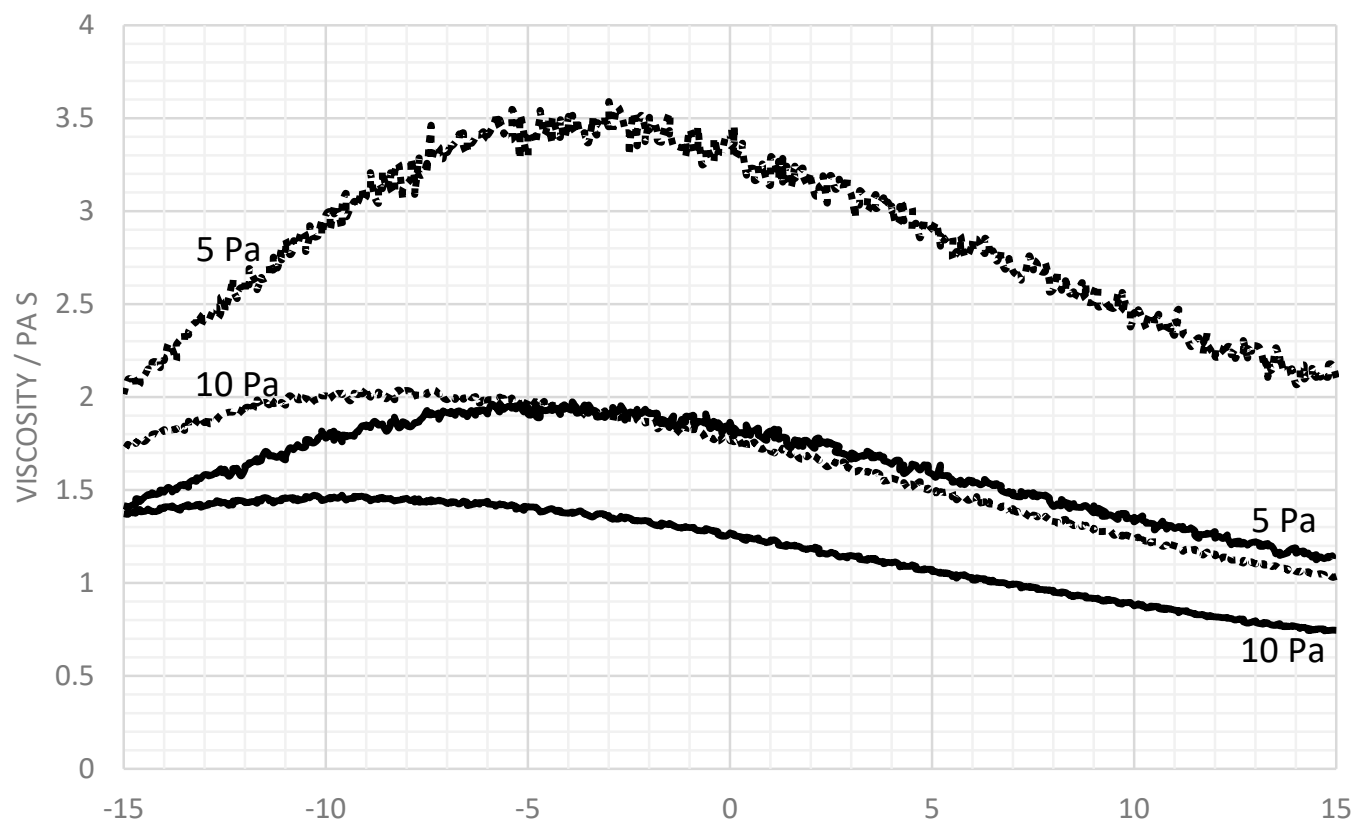

TEMPERATURE $/{ }^{\circ} \mathrm{C}$

Figure 6. Viscosity variation for Carbomer A with $0.03 \mathrm{wt} \%$ of $\mathrm{K}^{+}(-)(\mathrm{A} 1 \mathrm{~K})$ and $0.03 \mathrm{wt} \%$ of $\mathrm{Na}^{+}(\cdots)$ $(\mathrm{A} 1 \mathrm{~N})$ at shear stresses of 5 and $10 \mathrm{~Pa}$.

A sample was prepared involving the partial replacement of the sodium chloride with potassium formate to contain a blend of $0.030 \mathrm{wt} \%$ of sodium ions and $0.045 \mathrm{wt} \%$ of potassium ions (A3K). This was compared to a sample containing $0.075 \mathrm{wt} \%$ of sodium (A3N) (Figure 8). A peak is again observed in the viscosity plot for $\mathrm{A} 3 \mathrm{~K}$, but is located at a different temperature from that for $\mathrm{A} 3 \mathrm{~N}$ 
(containing only sodium ions). The peak in the viscosity plot is indicative of the dynamic characteristics of the polymer, and the shift reflects the way in which the replacement of sodium by potassium ions influences the aggregation, size, and shape of the PAA and its effective shear rate dependence.

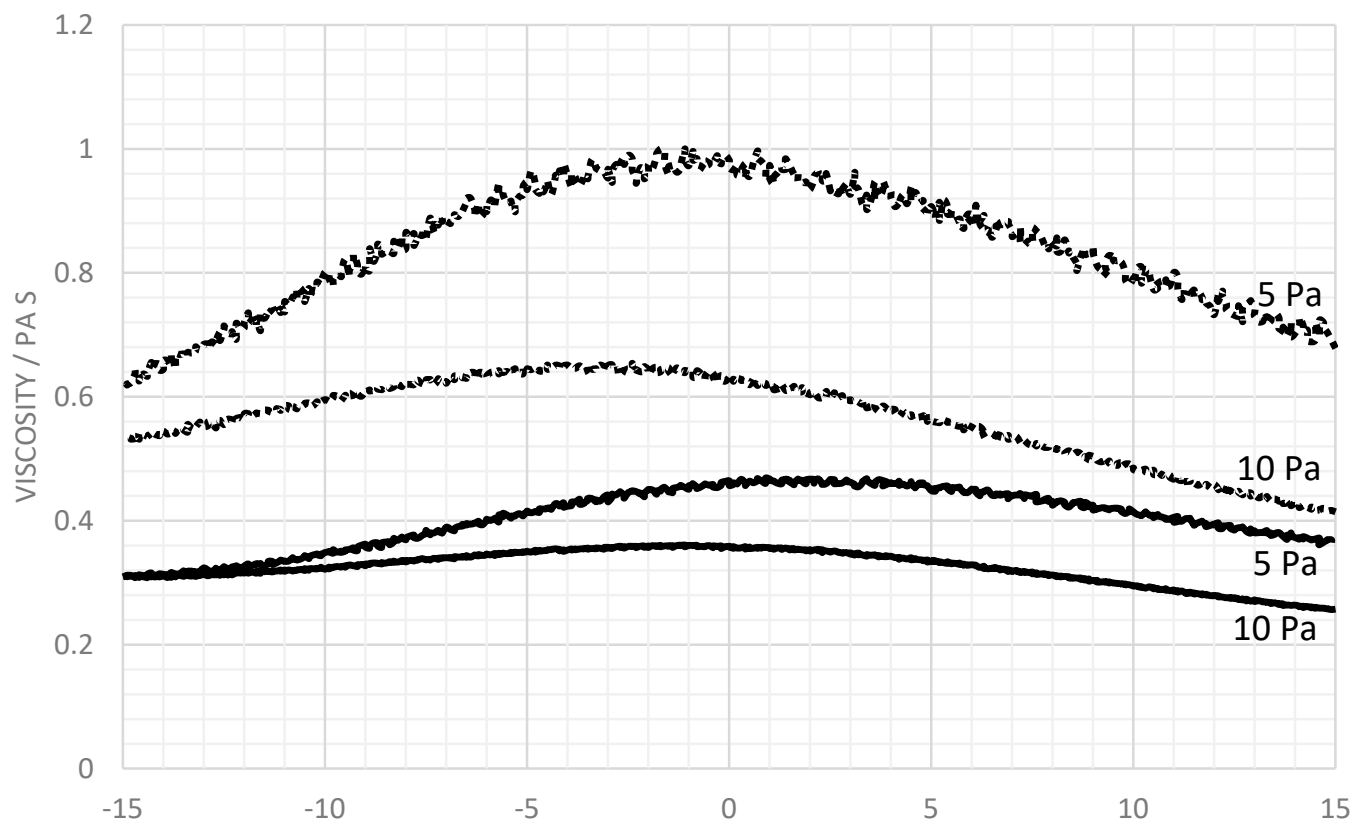

TEMPERATURE $/{ }^{\circ} \mathrm{C}$

Figure 7. Viscosity variation for Carbomer A with $0.06 \% \mathrm{~K}^{+}(\mathrm{A} 2 \mathrm{~K})(-)$ and $0.06 \% \mathrm{Na}^{+}(\mathrm{A} 2 \mathrm{~N})(\cdots)$ at shear stresses of 5 and $10 \mathrm{~Pa}$.

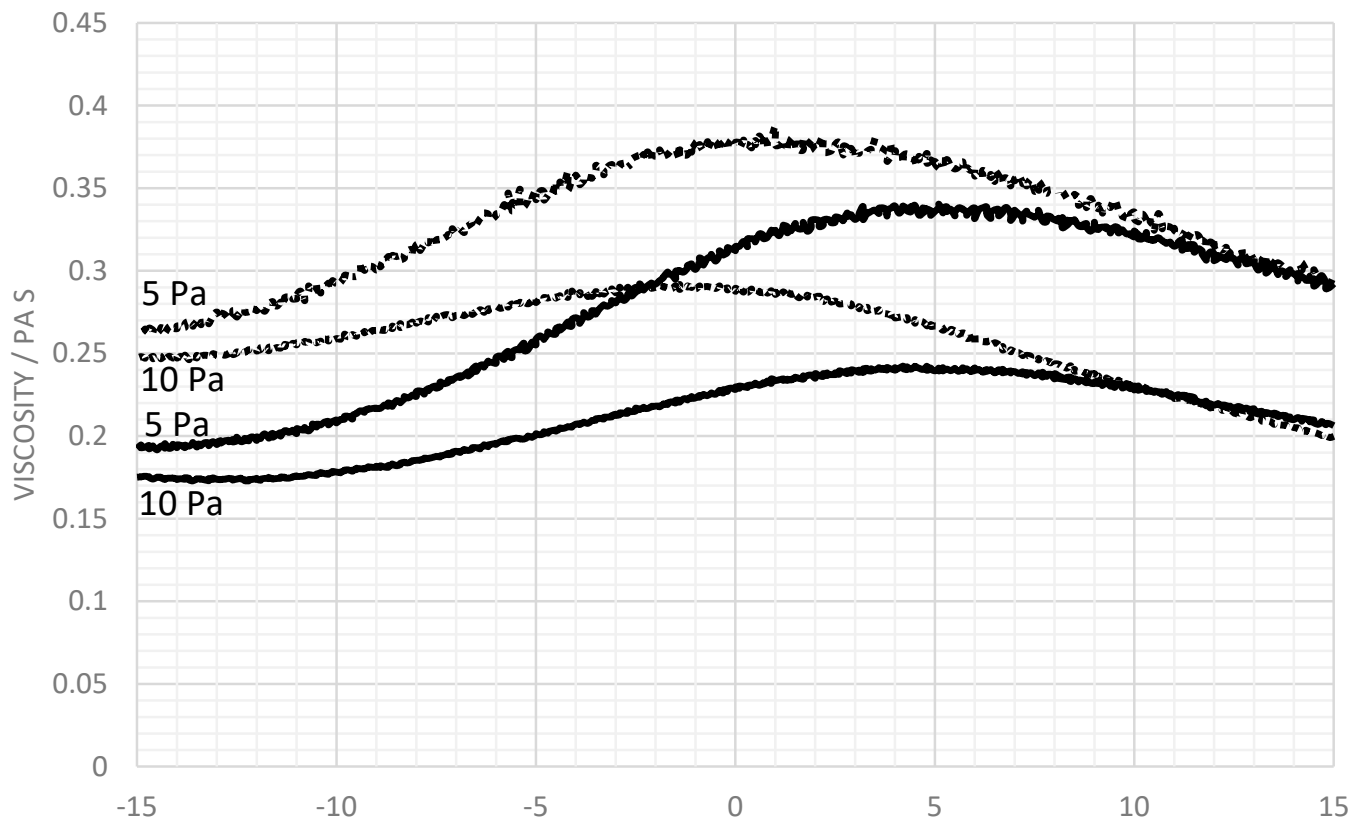

TEMPERATURE $/{ }^{\circ} \mathrm{C}$

Figure 8. Viscosity variation for Carbomer A containing $0.030 \mathrm{wt} \% \mathrm{Na}^{+}$and $0.045 \mathrm{wt} \% \mathrm{~K}^{+}(\mathrm{A} 3 \mathrm{~K})(-)$, and $0.075 \mathrm{wt} \% \mathrm{Na}^{+}(\mathrm{A} 3 \mathrm{~N})(\cdots)$ at shear stresses of 5 and $10 \mathrm{~Pa}$. 
The detection of a maximum in the viscosity and the related reduction in the temperature dependence of the viscosity is a necessary requirement for a de-icing fluid to be able to operate over an effective temperature range.

Figures 6-8 indicate a decreasing viscosity with increasing cation concentrations for the applied shear stress. There is also a shift in the peak temperature, although, importantly, the variation of viscosities across the temperature range remains low in all cases.

\section{Discussion}

Calcium, potassium, and sodium are known to interact with PAA (Carbomer A) polymers in various ways. The electrolytes can have two effects: They can shield the acid groups from interactions. The polymer molecules in the limit of complete shielding would appear like flexible polymer molecules. This would be the case for electrolytes which contains monovalent cations. In the case of bivalent cations, there is the possibility of the creation of bridges between acid groups in the polymers as well as adjacent polymers, enhancing interactions. Since potassium belongs to the same main group as sodium, it would be expected to behave similarly to sodium to shield the carboxyl groups. However, due to its larger ionic radius, the potassium cation has a greater binding power, and potassium formate demonstrates an increased ability to suppress the viscosity compared to sodium chloride.

Conductometric measurements [38] indicate that sodium ions exchange between bound and free states, in which one exchanges relatively quickly and is associated with ions lightly bound to the carboxylate groups, while the other is much slower and involves exchange of ions associated within the coiled polymer chain. The proportion of bound and free ions is influenced by $\mathrm{pH}$ and the total electrolyte concentration. Calcium ions can form bridges between chains where precipitation occurs if the concentration is sufficiently high $[39,40]$. The point at which precipitation occurs depends on the concentration of $\mathrm{NaCl}$, which influences the sizes and shapes of the polymer chains, as revealed by using light scattering. At lower $\mathrm{NaCl}$ concentrations, the polymer chains adopt a pearl necklace-like structure intermediate, but can collapse to a coil structure, which can be re-expanded by increasing the concentration of $\mathrm{NaCl}$. The changes to the polymer shape and size reflect the effects of temperature on the distribution between bound and free ions [41]. Resonance Raman Scattering has shown that the sizes of the polymer chains change with $\mathrm{pH}$ and $\mathrm{NaCl}$ concentration, with the dimensions increasing and decreasing as a consequence of changes in external stimuli [42].

The observed maximum in the temperature dependence of the viscosity is a direct result of the distribution of cations bound to the polymer chain to those remaining in solution. In this paper, we were able to show that a maximum in the viscosity-temperature profile coincides with the rheological requirements for a good de-icing fluid. Combined with data from a previous study [1], it is therefore possible to formulate some guidelines with regards to the design of a de-icing fluid:

(1) The base liquid, which is usually a glycol, is required to have a melting characteristic which is lower than the lowest operational temperature for the fluid. Propylene glycol is more favorable than ethylene glycol from an environmental point of view, but is limited in terms of its low temperature performance $[13,15]$. The viscosities of such mixtures at $0{ }^{\circ} \mathrm{C}$ and above are insufficient to maintain a stable ice covering prior to the aircraft taxiing, and are required to be thickened to achieve the desired rheological profile. The rheological effects of using ethylene glycol are not considered in this study.

(2) The thickener, which is often poly(acrylic acid)-based, raises the viscosity at intermediate temperatures. Ideally, it should not significantly enhance the viscosity at the lowest temperatures. The de-icing fluid is required to be shear-thinning for removal during the initial stages of take-off. Above a concentration of $0.245 \mathrm{~g} \mathrm{dL}^{-1}$, association occurs between polymer molecules. The studies were performed at a concentration of $0.3 \mathrm{~g} \mathrm{dL}^{-1}$, as this had been found from the previous study to have the desired characteristics for a de-icing fluid [1]. At this concentration, the extended chains are able to create a transient network which shear-thins on application of the forces created during the initial acceleration of the aircraft during take-off. 
(3) The concentration of salt is dictated by its ability to interact with polyacrylic acid. If the $\mathrm{pH}$ of the solution is adjusted to around 7.0, the carboxylic groups will be partially ionized and become capable of interaction with the cations present in solution.

(4) The addition of antioxidants and corrosion protection agents can also influence the gelation of the residues, and can therefore impact on the stability of the gel deposited in the ailerons and under wing areas, which are noted as being shielded from regions of high turbulence and shear. Similar temperature profiles have been obtained using polyvinylpyrrolidone-PAA mixtures stabilized with electrolytes and dispersed in water glycol mixtures, making them suitable candidates for de-icing fluid thickeners.

(5) In the context of the possible effects which the sodium or potassium formate might have on the de-icing formations, the following comments can be made:

(i) The monovalent cations can bind to the carboxyl groups of the polymer, but in doing so they create an ion pair which blocks the possibility of hydrogen bonding with the groups on the same molecule or between adjacent polymer molecules. The net effect is an inhibition of stable gel formation.

(ii) The presence of the sodium or potassium formate will influence the ionic strength of the 'solution', and this normally has the effect of lowering the viscosity and hence inhibiting polymer-polymer interactions.

\section{Conclusions}

This study shows that there is temperature dependence associated with the shear rate of the viscosity of de-icing fluids and also influenced by the nature of the ions present in the water used in their dilution. There is a clear difference in viscosity-shear rate-temperature due to the strengths of interactions between monovalent sodium and potassium ions with the carboxylic acid groups on the PAA polymer. This will consequently influence the performance of the fluids. It is apparent that mixtures of sodium and potassium with the same ionic strength do not have the same ability to induce the same state of aggregation and structure in the polymers as when sodium chloride is used by itself. As would be expected, bivalent calcium ions are able to promote gel formation, which is reflected in the viscosity behavior. This raises a cautionary note on the effects of hard water dilution on the performance of the de-icing fluids. From this study of the effects of ion content in water used in the preparation of de-icing, it is therefore possible to propose guidelines for their design, providing that the ion content is known, to achieve the desired rheological properties.

Author Contributions: Y.W. was responsible for undertaking all laboratory and experimental work, and data analysis. N.E.H. completed the analysis of the rheological data. R.A.P. was responsible for the interpretation of the polymer chemistry. C.J.S. was responsible for overall management of the project, including funding, and was responsible for the process engineering analysis.

Acknowledgments: The financial support of Kilfrost Limited in the form of a studentship for Yuchen Wang and the use of the wind tunnel testing facility is gratefully acknowledged. The advice in the preparation of this manuscript by John Liggat at the University of Strathclyde is also gratefully acknowledged.

Conflicts of Interest: The authors declare no conflict of interest.

Dedication: This publication is dedicated to Professor Richard (Dick) Pethrick who sadly died during the latter stages of the preparation of this manuscript.

\section{References}

1. Wang, Y.; Pethrick, R.A.; Hudson, N.E.; Schaschke, C.J. Rheology of poly (acrylic acid) in water/glycol/salt mixtures. Ind. Eng. Chem. Res. 2013, 52, 594-602. [CrossRef]

2. Blau, K. Recommendations for De-Icing/Anti-Icing Aeroplanes on the Ground, 30th ed.; AEA Publications: Nashville, TN, USA, 2015. 
3. D'Avirro, J.; Chaput, M.D.; Board NECTAR. Optimizing the Use of Aircraft De-icing and Anti-Icing Fluids; Transportation Research Board: Airport Cooperative Research Program (ACRP); United States Fire Administration (USFA): Washington, DC, USA, 2011.

4. Sapienza, R.; Johnson, A.R.; Ricks, W.F. Environmentally Benign Anti-Icing or De-Icing Fluids. U.S. Patent No. 6,506,318, 14 January 2003.

5. Hille, J. De-Icing and Anti-Icing Fluid Residues, Aero; Boeing Commercial Airplanes Group: Seattle, WA, USA, 2007; pp. 14-21.

6. Buttner, K. German Federal Bureau of Aircraft Accidents Investigation; Bundesstelle für Flugunfalluntersuchung: Braunschweig, Germany, 2005.

7. Cal, A. Training Recommendations and Background Information for De-Icing/Anti-Icing of Aircraft on the Ground, 5th ed.; AEA Publications: Pittsburgh, PA, USA, 2008.

8. Beisswenger, A.; Laforte, J.-L.; Trenblay, M.-M.; Perron, J. Investigation of a New Reference Fluid for Use in Aerodynamic Acceptance Evaluation of Aircraft Ground De-Icing and Anti-Icing Fluid; Federal Aviation Administration: Washington, DC, USA, 2007.

9. Simonot, M.; Mischka, G.; Holland, N. Recommedations for De-Icing/Anti-Icing of Aircraft on the Ground, 19th ed.; AEA Publications: Pittsburgh, PA, USA, 2004.

10. Jenkins, R.D.; Bassett, D.R.; Lightfoot, R.H.; Boluk, M.Y. Aircraft Anti-icing Fluids Thickened by Associative Polymers. WO Patent No. 9,324,543, 1993.

11. Seiler, M.; Bernhardt, S. De-Icing Agent and/or Anti-Icing Agent, C09K 3/18 ed.; USPTO, Ed.; Evonik Degussa GmbH: Essen, Germany, 2011.

12. Dow, J.P. Understanding the stall-recovery procedure for turboprop airplanes in icing conditions. In Flight Safety Digest; Flight Safety Foundation, Inc.: Alexandria, VA, USA, 2005; pp. 1-17.

13. Mohiley, A.; Franzaring, J.; Calvo, O.C.; Fangmeier, A. Potential toxic effects of aircraft de-icers and wastewater samples containing these compounds. Environ. Sci. Pollut. Res. 2015, 22, 13094-13101. [CrossRef] [PubMed]

14. Kent, R.A.; Andersen, D.; Caux, P.-Y.; Teed, S. Canadian Water Quality Guidelines for Glycols, an Ecotoxicological Review of Glycols and Associated Aircraft Anti-Icing and Deicing Fluids. Environ. Toxicol. 1999, 14, 481-522. [CrossRef]

15. Corsi, S.R.; Geis, S.W.; Loyo-Rosales, J.E.; Rice, C.P.; Sheesley, R.I.; Failey, G.G.; Cancilla, D.A. Characterization of Aircraft Deicer and Anti-Icer Components and Toxicity in Airport Snowbanks and Snowmelt Runoff. Environ. Sci. Technol. 2006, 40, 3195-3202. [CrossRef] [PubMed]

16. Stanley, M.E.; Smith, K.W. De-Icing, C09K003/18 ed.; USPTO, Ed.; Clearwater, Inc.: Richmond, VA, USA, 2003.

17. Ritter, S. What's that stuff? Chem. Eng. News Arch. 2001, 79, 30. [CrossRef]

18. Paredes, X.; Pensado, A.S.; Comunas, M.A.J.P.; Fernandez, J. Pressure effects the Dynamic Viscosities of Two Poly(propylene glycol) Dimethyl Ether Lubricants. J. Chem. Eng. Data 2010, 55, 4088-4094. [CrossRef]

19. Coffey, D.A.; Nieh, E.C.Y.; Armstrong, R.A. Aircraft Deicing Fluid with Thermal and $p H$-table Wetting Agent; USPTO, Ed.; Texaco Inc.: Beaumont, TX, USA, 1995.

20. Jenkins, R.D.; Bassett, D.R.; Lightfoot, R.H.; Boluk, M.Y. Aircraft Anti-Icing Fluids, C08K 505 ed.; USPTO, Ed.; Union Carbide Chemicals \& Plastics Technology Corporation: Wilmington, DE, USA, 1995.

21. Jenkins, R.D.; Bassett, D.R.; Lightfoot, R.H.; Boluk, M.Y. Aircraft Anti-Icing Fluids Thickened by Associative Polymers, C08K 505 ed.; USPTO, Ed.; Union Carbide Chemicals \& Plastics Technology Corporation: Wilmington, DE, USA, 1997.

22. Ross, F. Aircraft De-Icing/Anti-Icer; USPTO, Ed.; Kilfrost Limited: Newcastle Upon Tyne, UK, 2011.

23. Bollinger, T.K.; Mineau, P.; Wickstrom, M.L. Toxicity of sodium chloride to house sparrows (Passer domesticus). J. Wildl. Dis. 2005, 41, 363-370. [CrossRef] [PubMed]

24. Hudson, N.E.; Ferguson, J.; Warren, B.C.H. Polymer complexation effects in extensional flows. J. Non-Newton Fluid Mech. 1988, 30, 251-266. [CrossRef]

25. Miquelard-Garnier, G.; Demoures, S.; Creton, C.; Hourdet, D. Synthesis and rheological behavior of new hydrophobically modified hydrogels with tunable properties. Macromolecules 2006, 39, 8128-8139. [CrossRef]

26. Ikegami, A.; Imai, N. Precipitation of polyelectrolytes by salts. J. Polym. Sci. 1962, 56, 133-152. [CrossRef]

27. Lubrizol Advanced Materials, I. Minimizing Influence of Salts in Presence of Carbopol Polymers; TDS-542002; Cleveland, $\mathrm{OH}$, USA. 
28. Louchez, P.R.; Laforte, J.L.; Bouchard, G.; Farzaneh, F. Laboratory Evaluation of Aircraft Ground De/Antiicing Products, 4th ed.; Chung, J.S., Karal, K., Koteryama, W., Eds.; International Society Offshore \& Polar Engineers: Cupertino, CA, USA, 1994; pp. 479-483.

29. Louchez, P.; Laforte, J.L.; Bouchard, G. Boundary Layer Evaluation of Anti-Icing Fluids for Commuter Aircraft; University of Quebec at Chicoutimi (UQAC): Chicoutimi, QC, Canada, 1994.

30. Louchez, P.; Laforte, J.L.; Bernardin, S. A Proposal of Standard Evaluation of Aerodynamic Performance of De-Icing and Anti-Icing Fluids Applied on Commuter Type Aircraft; Universite du Quebec a Chicoutimi: Chicoutimi, QC, Canada, 1994.

31. Renton Division Aerodynamics Engineering. Aerodynamic Acceptance Test for Aircraft Ground De-Icing/Anti-Icing Fluids; Boeing: Chicago, IL, USA, 1992.

32. SAE. SAE AS5901B Water Spray and High Humidity Endurance Test Methods for SAE AMS1424 and SAE AMS1428 Aircraft De-Icing/Anti-Icing Fluids; SAE International: Warrendale, PA, USA, 2010.

33. Chu, J.S.; Yu, D.M.; Amidon, G.L.; Weiner, N.D.; Goldberg, A.H. Viscoelastic Properties of Polyacrylic-Acid Gels in Mixed-Solvents. Pharm. Res. 1992, 9, 1659-1663. [CrossRef] [PubMed]

34. Tsvetkov, V.N.; Lyubina, S.Y.; Barskaya, T.V. The flow birefringence and viscosity of poly (acrylic acid) solutions. Polym. Sci. USSR 1964, 6, 886-892. [CrossRef]

35. Takahashi, A.; Nagasawa, M. Excluded Volume of Polyelectrolyte in Salt Solutions. J. Am. Chem. Soc. 1964, 86, 543-548. [CrossRef]

36. Yaoita, T.; Isaki, T.; Masubuchi, Y.; Watanabe, H.; Ianniruberto, G.; Marrucci, G. Primitive Chain Network Simulation of Elongational Flows of Entangled Linear Chains: Role of Finite Chain Extensibility. Macromolecules 2011, 44, 9675-9682. [CrossRef]

37. Marrucci, G.; Bhargava, S.; Cooper, S.L. Models of shear-thickening behaviour in physically cross-linked networks. Macromolecules 1993, 26, 6483-6488. [CrossRef]

38. Wall, F.T.; Grieger, P.F.; Huizenga, J.R.; Doremus, R.H. Electrolytic Properties of Aqueous Solutions of Polyacrylic Acid and Sodium Hydroxide. III. The Rate of Sodium Ion Exchange between Polyacrylate and Free Sodium Ions. J. Chem. Phys. 1952, 20, 1206-1211. [CrossRef]

39. Miyajima, T.; Mori, M.; Ishiguro, S.-I. Analysis of Complexation Equilibria of Polyacrylic Acid by a Donnan-Based Concept. J. Colloid Interface Sci. 1997, 187, 259-266. [CrossRef] [PubMed]

40. Pochard, I.; Foissy, A.; Couchot, P. Conductometric and microcalorimetric analysis of the alkaline-earth/ alkali-metal ion exchange onto polyacrylic acid. Colloid Polym. Sci. 1999, 277, 818-826. [CrossRef]

41. Schweins, R.; Huber, K. Collapse of sodium polyacrylate chains in calcium salt solutions. Eur. Phys. J. 2001, 5, 117-126. [CrossRef]

42. Li, Y.; Chen, X.; Zhang, M.; Luo, W.; Yang, J.; Zhu, F. Macromolecular Aggregation of Aqueous Polyacrylic Acid in the Presence of Surfactants Revealed by Resonance Rayleigh Scattering. Macromolecules 2008, 41, 4873-4880. [CrossRef]

(C) 2019 by the authors. Licensee MDPI, Basel, Switzerland. This article is an open access article distributed under the terms and conditions of the Creative Commons Attribution (CC BY) license (http://creativecommons.org/licenses/by/4.0/). 